\title{
Exploration and Improvisation: The Use of Creative Strategies in Instrumental Teaching
}

\author{
Lídia Moreira $^{1}$, Sara Carvalho ${ }^{2}$ \\ Aveiro University ${ }^{1,2}$, INET-MD ${ }^{2}$, Portugal
}

\begin{abstract}
In music lessons there are still predisposition to adopt some educational practices, where the teaching is still centered in the teacher, and the student is there to "imitate" and learn the music exercises brought into class. By doing so the teacher is neglecting the student musical development as there is a unidirectional skill transfer, and the student does not participate directly in the process.
\end{abstract}

Therefore, using creative strategies in class maybe a striking and important element, that can both create student participation but also allow different dynamics within the classroom.

In music, instrumental classes share a set of common skills to other music disciplines, in which the use of musical exploration and improvisation activities can present in various ways. The importance of incorporating these activities in teaching students how to play an instrument, points to their individual needs and presents itself as a vehicle to promote further technical and expressive developmental skills.

The present paper focuses on two case studies, with both students at the beginning of their learning.The study intend to demonstrate the impact of musical exploration and improvisation in the technical and musical evolution of the student within the context of studying the violoncello. The results' analysis led to a discussion that could serve as a proposal for strategies on teaching-learning to play an instrument.

The paper concludes that the students, who attend classes with the use of creative activities as a teaching strategy, obtain more emphatic results and success.

\section{Introduction}

The use of creative activities in instrumental musical teaching classes could lead to advantages in the development of expressive and technical abilities in instrument playing. This paper's focal point is to evaluate the benefits of creativity - in particular, the benefits of musical exploration and improvisation regarding the acquisition and/or correction of expressive and technical skills on cello students, contributing to a reflection about instrumental teaching strategies, and how creative activities may lead to educative development and success.

\section{Literature Review}

After the 1970s, several approaches to the study of creativity developed by authors such as Sternberg, Amabile and Csikszentmihalyi, attribute a group of factors to creative production which, through complex interaction, refer to the individual as much as to the social, cultural and historical variables that surround them.

For Radford creativity may be seen as a complex process of information processing, which is present in the variables of a conceptual space resulting in multiple possibilities in terms of meaningful articulations. The author adds that "it is important to give full cognizance to the complexity of the information-processing task being performed and it is highly doubtful if all elements, all items of information, and the relationships between them, are before the conscious mind of the individual creative intelligence at any one time" [14]. Radford also mentions that there is a need to recognise the existence of an emotional dimension in learning, that learning and intelligent thought require emotional dispositions for certain types of knowledge and construction, and that the creative individual has to feel the challenge, the desire to reconcile unknown elements with the information system.

For Csikszentmihalyi "the creative process begins with the goal of solving a problem that is given to the person by someone else or is suggested by the state of the art in the domain" [8]. The author also adds that the creative act involves the production of novelty, stating that this discovery process seems to be one of the most satisfying human activities.

Many music teachers have the tendency to adopt a more traditional teaching strategy, as mentioned by DePascale [9], which may be hindering the transfer of skills to enable students to learn and grow from a positive self-criticism [13].

Creative activities, which are usually included in music classes, have showed great advantages in the development of several skills in students. 
Consequently, many authors have been researching the topic creativity, and its role in the educational context.

According to Amabile and Gryskiewicz [2], the creative process is somewhat elusive; the authors claim that little is still known about the process of creative thinking, although they also mention that several researchers have been successful while studying products and creative ideas, creative people, and environments that promote creativity. Julie Scott [16], twenty years later, specifically speaking on the musical context, writes that the inclusion of creative activities in music classes means that students develop better technical, aural and reading skills. The author also states that when students do not think in musical notation, they concentrate more on the technical aspects and how the sound is produced.

Cropley [7] adds that creativity arises from a variety of psychological characteristics which include expertise, creative skills, motivation and selfconfidence. According to the author, in the context of the classroom, the teacher should take into account: all information, the different ways to thinking about this information, creativity to find solutions, talent to evaluate ideas, ability and willingness to communicate solutions to others, and to evaluate solutions into an appropriate context [7].

The study of metaphors has become an interdisciplinary research topic popular amongst the cognitive sciences such as linguistics, philosophy, psychology, artificial intelligence and literature, as well as other related disciplines such as education and psychotherapy [17]. In fact, according to Botha, there is widespread recognition that metaphors reveal an important role both at an aesthetic level, but also educational one [4].

According to Lubart and Getz, emotions are seen as structures organised by biological, social and psychological factors and show how emotions can be involved in the production of metaphors that lead to creative ideas. When discussing metaphors and their role in creativity, it is important to note that metaphors make comparisons that may provide new perspectives to problems, as well as form or widen our initial perspective of the problem and communicate new ideas to a vast [12].

"Metaphors enable us to make new connections and see things in a new way" [6]. For Bump the mastery of metaphor is the way to see old things in new ways, connecting objects and ideas that seem different, which achieve something deeper, more fruitful hypotheses and more comprehensive and effective models. The author states further, metaphorical thinking is a natural extension of logical thought, and refers to a technique used in the classroom (brainstorming), that demonstrate how the metaphorical thinking can help to solve practical problems, or that metaphors can help progress in problem solving situations [6].
Creativity and improvisation have an important role in teaching music. Azzara indicates that improvisation happens when "an individual has internalized a music vocabulary and is able to understand and to express musical ideas spontaneously, in the moment of performance" [3]. He adds that there are important factors to consider in defining improvisation, such as the process of expressing musical thoughts and emotions, creating music within certain structures previously learnt and producing musical discourse.

In truth, when researching the role of improvisation within the context of the classroom, Azzara states that "improvisation allows students to express themselves individually, to develop higher order thinking skills, and to develop a more comprehensive and intimate relationship with music (...)" [3]. For the author, it is important to develop improvisation in the community, develop an atmosphere where improvisation, spontaneity and interaction are nourished, understand improvisation as a way of life and not just an activity, believe that improvisation may be developed and that all students have the potential to improvise, observe that improvisation can affect other musical skills, and incorporate a model to develop improvisation skills that will help teachers as well as students [3].

In an attempt to find an answer as to how to teach students to improvise, Kenny and Gellrich [11] suggest two strategies: transcendence and deliberate practice. Transcendence, as understood by the authors, is a state of consciousness that reaches beyond the knowledge accumulated within you, whereas the primary objective of deliberate practice is to stimulate the development of improvisation skills through the bases of acquired knowledge [11]. The authors also add that it is important that group activities complement individual practice. Although individual practice is beneficial to the development of technical and theoretical principles, improvisation emphasises collective performance more. Creative improvisation generally occurs in a collective performance atmosphere as opposed to an individual lesson, and the ability to react and create music through unpredictable dynamics and variables is one of the most distinct aspects of improvisation [11].

However, according to Bradshaw there are some obstacles to collective improvisation: with no doubt the most problematic of them is the possibility that the individual may fear being ridiculed by their colleagues. For Bradshaw, improvisation contains an element of risk that is not attractive to the common student; however, he builds on this idea by suggesting that " $a$ teacher can reduce the sense of risk by keeping an open atmosphere in class and by participating” [5].

Complementing Bradshaw's perspective, Riveire [15] considers it important to evaluate the level of anxiety that the student, as well as the teacher, may 
feel in improvisation activities. Riveire notes the importance of eliminating high levels of anxiety in order to allow for musical thought to flow, and therefore suggests that the atmosphere created should stimulate confidence. Riveire also highlights that various teaching strategies emphasise the importance of manipulating an idea or skill to enrich learning. In music, the manipulation occurs using the body or mind with the objective of exploring different ways of making music, using a specific sound or a combination of sounds [15]. According to the author, the way that the musical material is manipulated when improvising causes the brain to process things differently, which in turn enhances the student's ability to learn. Riveire also writes that improvisation acts at the most advanced levels of the cognitive process (attention, analysis and synthesis), further adding that the implementation of this strategy in teaching music is a rewarding effort.

\section{Methods and Methodologies}

The aims of this study was primarily to understand how musical exploration and improvisation act in the development of technical and expressive skills in children. Other objects of the research are to verify if musical exploration and improvisation activities in teaching and learning an instrument can solve technical difficulties, to assess technical and musical development of students involved in the study, and finally to analyze and discuss the results.

While setting up this study several questions were raised: What impact musical exploration and improvisation activities have as a teaching/learning tool? Are there critical periods to include these activities in the classroom?

In an attempt to answer the questions presente, we highlight two aspects that deserve our attention: 1) the importance of observing the student in the instrumental class, and assessing his/her performance in the activities without musical exploration and improvisation, thus clarifying his/her technical and musical level; 2) the subsequent observation, and analysis his/her performance, while incorporation activities with musical exploration and improvisation. Therefore, we suggest that the incorporation of this activities in all instrumental classes, have the objective not only to promote technical and musical development of student, but also to verify if this activities are important dimensions that should complement and improve instrumental development.

In the first phase of this study, we evaluated the level of both students, giving special attention to technical and musical difficulties that occurred in the context of a class, and had not been sorted by the student. In a second phase, the activities of exploration and improvisation were incorporated in the instrumental classes, in an attempt to solve both technical and musical difficulties revealed by the students involved in the study. Their technical and musical progress was evaluated.

It is worthwhile noting that this research examined the obstacles, and challenges, of incorporating improvisation and exploration activities in the instrumental class, as well as how one can overcome them, promoting developmental skills of the students in the teaching/learning process.

The methodology used in this study is experimental and comparative. This methodological process consists of field work in addition to participant observation, which was based on bibliographical research techniques and action research, combined with a video recording and subsequent comparative analysis of data gathered.

\subsection{Participants on the study}

This research focused on two case studies with two students, one 10 years of age (Student $A$ ) and the other 14 years of age (Student $B$ ), both in the $1^{\text {st }}$ year of studying cello (" $1^{\circ}$ Grau do $2^{\circ}$ Ciclo do Ensino Básico de Violoncelo" of the Portuguese Conservatory System).

Student A had never taken instrumental classes before; however, always showed great interest for the violoncello lessons, showing always motivation to learn the class contents suggested in the program. Student B also began his violoncello studies at the beginning of this research, but in addition, this student attended piano classes at the Conservatory. Throughout the investigation the student showed enough interest in cello lessons, working essentially the main the class contents suggested in the program points included in the program established.

The students were observed for approximately 8 months. At the beginning of the school year, Student A had classes together with Student B, who was in the same level; though, at the end of two months, they began to have individual lessons, because it proved to be more suitable for the development of both students.

In order to demonstrate the impact of musical exploration and improvisation in the technical and musical evolution of these students, who were beginning to learn the instrument, three specific objectives were established:

1) To understand if the musical exploration and improvisation influence the development of technical and expressive skills;

2) To verify if, in the introduction to learning an instrument, musical exploration and improvisation can help solve technical and musical difficulties;

3) To observe, analyse and evaluate the technical and musical evolution of the two students involved in the study. 
According to Figure 1, in order to check the objectives proposed, the 2 students had approximately 5 months of cello lessons without musical exploration and improvisation activities; during this period the students had a 30 minute individual lesson per week, however they always watched each other's lesson. Next, the 2 students had approximately 3 months of cello lessons with musical exploration and improvisation activities; during this period the students had 20 minutes of individual lessons per week, and they always watched each other's lesson, and in the remaining 20 minutes they had a joint lesson with musical and improvisation exploration activities.

\subsection{Activity plan for the sessions}

The strategies used for classes without musical exploration and improvisation were based on the $1^{\text {st }}$ Grade of the Cello Curriculum, and the exercises were carried out individually. At the end of four months of classes, sessions with musical exploration and improvisation were included in the beginning of all students' instrumental classes.

During the sessions that used creative activities, opportunities were created for children to experiment with sound through an active pedagogy: (1) exploration of the sounds that the body produces, that were later "transposed" to the cello, with the objective to resolve muscular tension problems; (2) exploration of sound dynamics - from forte to piano - in order to control the movements of the right hand, right arm, the sound of the bow and the general produced sound quality, (3) exploration of small melodies in the first position, with the aim of improve the right hand position, and fingers, and their consequent adjustment, (4) exploration of small melodies in the first position, with the aim to improve the left hand position (mainly the position the 3rd finger), and the resulting pitch and volume control on the right hand; (5) exploration of small melodies using initially just pitches produced in the first position on one string, and then with the extension of the 4th finger - the purpose of the exercise was to improve the position of the left hand and fingers both to perform the first position as well as the extension of the 4th finger, differentiating and memorizing the mechanism of adaptation to each situation, therefore improving the tuning of the left hand and sound control of the right hand, (6) exploration of small melodies to improve the position of the left hand and fingers as much to run the first position, as well as extension of 1st finger, using two strings, differentiating and memorizing the mechanism of adaptation to each situation, therefore improving the left-hand tuning and volume control on the right hand.

As a result, instrumental sessions had a preestablished sequence as can be observed in Figure 1.

\begin{tabular}{|c|c|c|}
\hline $\begin{array}{l}5 \text { months of cello } \\
\text { lessons } \\
\text { without musical } \\
\text { exploration and } \\
\text { improvisation } \\
\text { activities }\end{array}$ & \multicolumn{2}{|c|}{$\begin{array}{l}30 \text { minute individual lesson } \\
\text { per week (students always } \\
\text { watched each other's lesson) }\end{array}$} \\
\hline $\begin{array}{l}3 \text { months of cello } \\
\text { lessons } \\
\text { with musical } \\
\text { exploration and } \\
\text { improvisation } \\
\text { activities }\end{array}$ & $\begin{array}{l}20 \text { minutes } \\
\text { of } \\
\text { individual } \\
\text { lessons per } \\
\text { week }\end{array}$ & $\begin{array}{l}20 \text { minutes } \\
\text { joint lesson } \\
\text { with musical } \\
\text { and } \\
\text { improvisation } \\
\text { exploration } \\
\text { activities }\end{array}$ \\
\hline
\end{tabular}

Figure 1. Sequence of cello lessons

Two distinct plans were designed; the first consisted of lessons without musical exploration and improvisation activities that were based on the Portuguese Conservatory curriculum; later, lessons with musical exploration and improvisation activities were planned based on observed technical and musical problems that the students in the case study had throughout the first 5 months of lessons, as observed in Figure 2 and Figure 3.

Objectives:

Body $\longrightarrow$ Instrument

1. To explore sounds that the body can produce;

2. To transcribe those sounds as graphic notation; 3 . To find equivalent sounds in the cello;

4. To organize those sounds as a "story", in a sequence.

Example made by Student $B$

1. "to yawn"

2. ר

3. To play a descendent glissando in the $4^{\text {th }}$ string

The aim of this session was to reduce muscular tension, which remained present after the first 5 months of lessons. At the end of the lesson, the student should know the different timbers that his instrument can produce, and should stay with the notion that his body can be consider an instrument. As a consequence he will be told to think that his instrument can be as natural as his body, and that the student should have the same naturality when playing the cello.

Figure 2. Example of lesson with musical exploration and improvisation activities

\section{Findings}

The results of the activities without musical exploration and improvisation will be presented individually to each student. The division will include both the objectives for each of the phases, as well as the evolution of the pupil concerned. 
The skills set for both students, were related to the movement of the bow across the strings, placing the left hand and fingers position (1st position), tying notes with the same bow movement, changing bows between strings with/without/within ligatures, and the extension mechanism.

During the first 5 months of lessons, without musical exploration and improvisation activities, Student A showed several difficulties. The main difficulties observed were in the relaxing and positioning of the right arm, and in the fingering of the first position - left hand. Due to the level of difficulty, extending the first and the fourth finger was also dealt with in the musical exploration and improvisation sessions in order to complement and further develop the mechanism of this execution.

The posture and relaxation exercises have been always looked after in the beginning of each class, to get the student internalize these aspects. This student showed progress at both relaxation level and right arm position. However, the student was always advised to keep practicing these exercises at home, to control better and better the sound produced.

Another aspect that the student showed great difficulties was the position of left hand (mainly the 1st finger), always playing a out of tune (low) pitch, always unable to distinguish tuned sound from a out of tune one. This was being observed in several classes, while trying to correct the left hand placement in first position. Although Student A had almost no theoretical basis, he/she could always read the notes in class, with relative ease.

As the sessions with musical and improvisation exploration activities integrated in the lessons commenced, Student A slowly began to reveal less difficulty in positioning the left hand in the exact place of the first position, and was able to distinguish, most of the times without assistance, if the sound was tuned or not (a feat which was virtually impossible before). The obvious improvements with regards to relaxing and the positioning of Student A's right arm were detected in the quality of the sound the student was able to make.

During the first 5 months of lessons without musical exploration and improvisation activities Student $B$ revealed having difficulties with posture and relaxing mainly affecting the sound produced by the bow - right arm. As in the case of Student A, due to the level of difficulty, extending the first and fourth finger was also addressed in the musical and improvisation exploration activities.

Student B showed progress in relaxation and position of the right arm, however, when he/she demonstrated some difficulties in achieving a better quality of the produced sound, the student was always advised to continue practice at home, to control better the sound produced.
Student B showed little difficulty in the position of the left hand (mainly the 1st finger), showing a relatively good ear. However, the student still needed several lessons to learn the proper placement of the left hand in first position. In class regarding all the exercises that encompassed musical notation, the student showed a lot of ease in reading.

During the period of musical and improvisation exploration activities Student $B$ also gradually began to show less difficulties in relaxing the right arm and started to improve posture. The quality of sound produced in the movement of the bow was the object of obvious improvement by the student, as less tension in the arm and right hand was observed.

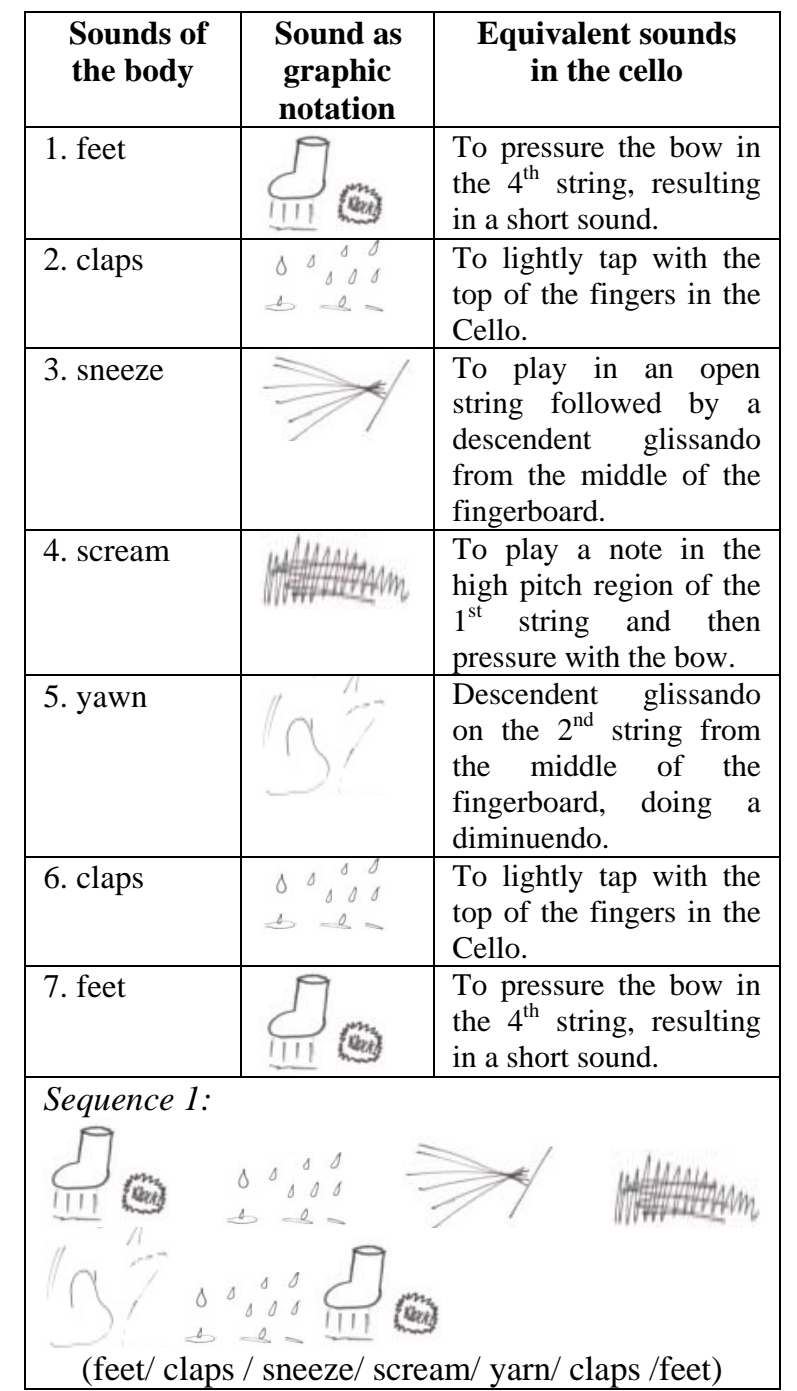

Figure 3. Final result (objective 4 of Figure 2) Sequence 1 by Student $B$ with musical exploration 5. Discussion and improvisation activities

Considering the general objective of this study, there is a need to make more of an effort towards a greater and more systematic appreciation when in comes to the influence of musical and improvisation 
exploration in the student's technical and musical development when beginning to learn how to play an instrument.

For Radford [14], creativity may be seen as a complex process of information processing. In fact, the students involved in this study were able to process information passed to them through new strategies based on creative activities, which allowed them to visualize new perspectives for its instrumental development. Finke [10] states that the mental transformation allows one to anticipate how something will be seen from a different perspective, facilitating both handling and creative exploration. In fact, it was possible to work with both students, anticipating every possible difficulty, observing the different optical character through creative activities they had done.

Analysing the result of the instrument lessons without musical exploration and improvisation activities, both students revealed to have difficulties that they were unable to solve during the 5 months, such as relaxing, posture and fingering. Of course both students involved in this study progressively developed in the playing of their instrument throughout this initial period; in truth, the teaching strategies applied during the lessons were always meant to promote the technical and musical evolution of each student, while particularly addressing the difficulties observed in an attempt to solve them.

Addressing the inclusion of creative activities in music classes, Julie Scott [16] states that the process leads students to develop some better musical skills. In this study, it was found that the inclusion of creative activities in cello lessons, led the students to think more in the way as the sound was produced. As pointed out by Csikszentmihalyi [8], the creative process begins with the aim of solving a problem, and this discovery process seems to be one of the most satisfying activities of human beings. The creative activities that were developed with the students, apparently "simplified" the technical aspects covered.

The observation of the musical and improvisation exploration activities that were incorporated in the cello lessons showed that with this type of activities the students may have a more complete opportunity to develop their technical and musical skills while overcoming the difficulties that they have. Consequently, the evolution of their learning becomes more efficient.

Having done research on the role of improvisation in the context of the classroom, Azzara states that improvisation allows the individual to express himself musically while developing their cognitive skills and their relationship with music [3]. The model of activities with musical and improvisation exploration, which was incorporated in the lessons of the students involved in this study, proved to be important and advantageous; in this context it was possible to help the students become conscious of their own difficulties and, by participating in the activities incorporated in a creative context, try to overcome them. It was also possible to observe that in this context the students could not only enrich their knowledge but also express themselves musically.

As Azzara [3] states all students have the potential to improvise and that the possibility of improvisation reach other musical skills, and students that have been exposed to such creative activities did not show maladjustment on the proposed tasks.

However, in approaching the obstacles and challenges that arise from incorporating activities with exploration and improvisation in the classes, it is important to emphasise the atmosphere of trust necessary in this type of activities. This may be affected by high levels of anxiety as referred to by Riveire [15] and Bradshaw [5]. During the sessions of musical and improvisation exploration it was possible to observe that the students became progressively more uninhibited as a result of trying to create a more relaxed and confident atmosphere in preparing for and doing activities with the students. This atmosphere of trust proved to be a starting point for the manipulation of the musical material explored making it possible to attain favourable conditions to develop the skills in question.

The initial addition of exercises based on metaphors in activities of musical and improvisation exploration helped the students make various comparisons that give them different perspectives on the problem/difficulty, as Lubart and Getz [12] make reference to in their study. It was possible for the students to broaden their initial vision and develop new ideas; later, these ideas unconsciously and spontaneously helped the students to develop instrumentally. In the context of instrumental pedagogy, Woody [18] reported a verbal alternative strategy that involves the use of imagery and metaphors. Moreover, the author noted that this type of instruction not only sorted technical performance, but mainly achieved all goals set to improved expressive performance. "Music educators heartily endorse the use of this approach, and musicians have shown themselves to be comfortable using it" [18], however, there might be potential problems - which may include some confusion and misunderstanding as the student may not fully understand the metaphorical language of the teacher. For Woody [18], the use of metaphorical language by the teacher aims to induce emotion, or describe expressive qualities of performance, but states that there is little research on the cognitive processes that allow students to use the method successfully.

The fact that these musical and improvisation exploration activities were carried out with both 
students simultaneously provided an interaction that gradually proved to be very positive, with both students progressively showing high levels of motivation.

\section{Conclusion}

Activities with musical and improvisation exploration have an influential impact on the student's technical and musical evolution. This impact, which was observed in this study, was progressive and came to complement the instrument development of the students. Curiously, the teacher/student relationship also benefited from this experience and created a deep bond resulting from the relaxed atmosphere that this type of activities demand, as this is probably a motivating experience in learning how to play an instrument.

Through the analysis of this study, it is also important to note that the various activities of musical exploration and improvisation incorporated as working tools in the instrument class provided an opportunity for students involved in this study to have a broader educational and active experience, which with another more traditional way, would probably be an utopia.

As a final note it is worth saying that the results of this research should be repeated with a larger sample size, so that data could have a better representation of what was proposed. Nevertheless, we hope that this was a meaningful contribution to the advancement of instrumental learning and teaching. Through the use of creative strategies in instrumental teaching both the casual and the systematized, can be integrated in order to provide a full development of each subject to be taught. The child does not only progress through several given concepts but she also constructs her own experience, as they participate in an emotional, cognitive and operational level.

\section{References}

[1] Alencar, E. M. L. S. and Fleith, D. S. (2003), "Contribuições Teóricas Recentes ao Estudo da Criatividade" in Psicologia: Teoria e Pesquisa. Vol.19 (no1) (pp. 001-008)

[2] Amabile, T. M., and Gryskiewcz, S. S. (1987), "Creativity in the R\&D Laboratory", Report, $n^{\circ} 30$, Center for Creative Leadership, Greensboro, N. C.

[3] Azzara, C. D. (2002), "Improvisation" in Colwell, Richard (ed), The New Handbook of Research on Music Teaching and Learning: a Project of the Music Educatores National Conference. Oxford: University Press.

[4] Botha, E. (2009), "Why metaphor matters in education" in South African Journal of Education. Vol. 29 (pp. 431-444)
[5] Bradshaw, M. (1980), "Improvisation and Comprehensive Musicianship" in Music Educators Journal. Vol.66 (nº5) (pp.113-115)

[6] Bump, J. (1985), "Metaphor, Creativity, and Technical Writing" in College Composition and Communication. Vol. 36 ( $\mathrm{N}^{\circ}$ 4) (pp. 444-453)

[7] Cropley, A. J. (1997), "Fostering creativity in the classroom: general principles" in Runco, Mark A. The Creativity Research Handbook Vol. 1. Hampton Press. (pp 83-114)

[8] Csikzentmihályi, M. (1996), "The flow of creativity” in Creativity: Flow and the Psychology of Discovery and Invention. New York: Harper Perennial.(pp 107-126)

[9] DePascale, R. (2003) "Classical connections: A creative way to learn classical music" in General Music Today, Vol.17 (nº) (pp 6-10)

[10] Finke, R. A. (1997), "Mental imagery and visual creativity" in Runco, Mark A. The Creativity Research Handbook Vol. 1. Hampton Press. (pp 183-202)

[11] Kenny, J. B. and Gellrich, M. (2002), “Improvisation” in Parcutt, Richard \& McPherson, Gary (ed), The Science and Psychology of Music Performance: Creative Strategies for Teaching and Learning. Oxford: University Press.

[12] Lubart, T. I. and Getz, I. (1997), “Creativity, Metaphor, and Creative Process" in Creativity Research Journal. Vol.10 (nº) (pp. 285-301)

[13] Odam, G. (1995), "Instrument teaching" in The Sounding Symbol - Music Education in Action. Nelson Thornes. (pp 103-122)

[14] Radford, M. (2004), "Emotion and Creativity” in Journal of Aesthetic Education. Vol.38 (nº1) (pp. 53-64)

[15] Riveire, J. (2006), "Using Improvisation as a Teaching Strategy" in Music Educators Journal. Vol.92 $\left(n^{\circ} 3\right)(p p .40-45)$

[16] Scott, J. K. (2007), "Me? Teach improvisation to children?” in General Music Today, Vol.20 (nº) (pp 6-13)

[17] Shen, Y. (1992), "Cognitive Aspects of Metaphor Comprehension: An Introduction” in Poetics Today. Vol. $13\left(n^{\circ} 4\right)$ (pp. 567-574)

[18] Woody, R. H. (2006), "The Effect of Various Instructional Conditions on Expressive Music Performance" in Journal of Research in Music Education. Vol. 54 (n $\left.{ }^{\circ}\right)$ (pp. 21-36) 